\title{
Place of residence does not significantly influence radiological morphology of cervical cancer
}

\author{
Franciszek Burdan,2, Agnieszka Mocarska', Robert Klepacz³, Jerzy Walocha4, \\ Tomasz Kubiatowski', Dariusz Surdyka', Dariusz Kieszko', Krzysztof Patyra', \\ Iwonna Żelazowska-Cieślińska', Elżbieta Starosławska' \\ 1 St. John's Cancer Center; Lublin, Poland \\ ${ }^{2}$ Human Anatomy Department, Medical Univeristy of Lublin; Lublin, Poland \\ ${ }^{3}$ Department of Clinical Pathomorphology, Medical University of Lublin; Lublin, Poland \\ ${ }^{4}$ Department of Anatomy, Jagiellonian University, Collegium Medicum; Krakow, Poland
}

Burdan F, Mocarska A, Klepacz R, Walocha J, Kubiatowski T, Surdyka D, Kieszko D, Patyra K, Żelazowska-Cieślińska I, Starosławska E. Place of residence does not significantly influence radiological morphology of cervical cancer. Ann Agric Environ Med. 2017; 24(3): 527-531. doi: $10.5604 / 12321966.1230729$

\section{Abstract}

Introduction and objective. Cervical squamous cell carcinoma is one of the most common malignancies of women. Its incidence and morphology was analyzed based on the magnetic resonance (MR) data among rural and urban residents.

Materials and method. The study involved 61 Caucasian women (58.26 \pm 9.63 years) preliminary diagnosed with a cervical cancer without any previous treatment. Standard MR examination, including diffusion weighted imagining, apparent diffusion coefficient (ADC) value measurement and dynamic contrast enhancement, was performed.

Results. The rural residents $(n=22)$ were insignificantly older. Their first and last menstruation were observed later and number of pregnancy was higher than in urban women $(n=39)$. However, the incidence of miscarriage was insignificantly rarer. All the tumour linear diameters as well as its volume were insignificantly higher in rural women. The ADC value of the cervical tumor was insignificantly lower, while ADC of lymphatic nodules was higher in rural women. Insignificant changes in tumour grade between both examined groups were found in histological, clinical and radiological examinations. Place of residence did not influence any clinical symptoms nor tumour volume and its ADC. Colporrhoea and colpodynia were insignificantly more often observed in urban women, while parametrium, urinary bladder and rectal infiltrations were more commonly seen in rural residents. Higher risk of lymphatic spread to the internal iliac and parametral lymphatic nodes was reported in the rural community.

Conclusion. Cervical cancer had similar morphology and growth pattern, regardless of the place of residence. However, a insignificantly larger tumour size among rural residents may suggest a higher incidence of lymphatic spread, probably as a result of less aaccess to modern health care.

\section{Key words}

cervical cancer, rural-urban differences, magnetic resonance, oncology

\section{INTRODUCTION}

Malignancies are the most common causes of death worldwide. Their incidence is implicated by genetic predisposition, gender, occupation, life style, education, socio-economic status, as well as various other environmental factors, including local and global pollution, geographical location and place of residence. According to GLOBOCAN [1] 12,662,600 new malignances were diagnosed worldwide and 7,564, 800 peoples died from them in 2008 alone. The most commonly reported were cancer of the lung, breast, colorectum, stomach and prostate, but there are number of gender differences. In males, the most common was lung cancer, followed by prostate, colon, stomach and liver, while in females, breast cancer rather than than colorectum, uterine cervix, lung and stomach. From all the selected organs the largest improvement was obtained only for cervical cancer due to its availability for systematic screening (i.e., Papanicolaou

Address for correspondence: Franciszek Burdan, St. John's Cancer Center; Lublin, Poland

E-mail: fb3@wp.pl

Received:19 August 2013; accepted: 25 February 2014; first published: January 2017 or liquid-based cytology) which helps to diagnose the disease in an early phase $[2,3]$. In countries with a good response to screening programmes the incidence drops significantly. Perhaps the best example of such a situation is Finland where the incidence decreased from 21.2 per 100,000 in 1996 to 7.3 per 100,000 in 2007 . However, such a positive trend has stopped in last few years, probably as a consequence of the widespread of human papilloma viruses (HPV) infection, the most important factor in cervical carcinogenesis. It is secondary to sexual behaviour changes, especially early initiation and increasing number of partners, but other sex-related factors should be also pointed out, like multiple pregnancies and labours, concomitant infections (Chlamydia trachomatis, Neisseria gonorrhoea, herpes simplex virus) of the genital tract, AIDS, immunosuppressive therapy, smoking and low socio-economic status. On the other hand, an increasing vaccination against HPV (type 18 and 16) may decrease the incidence of cervical cancer in the near future. However, none of vaccines prevent against HPV45 which is also regarded as a risk factor [2].

The above-mentioned behavioural changes are well-seen, especially among rural and urban residents [4-6]. Presently, 
due to higher access to the Internet and mass-media such differences are not so high, but in the past an early sexual initiation was reported most commonly in persons from villages and small towns, especially in less-developed countries $[5,6]$.

Since sexual behaviour is a risk factor for cervical cancer, the aim of the study was to evaluate differences of the neoplasm among rural and urban residents, based on radiological data.

\section{MATERIALS AND METHOD}

The study was conducted on the retrospective data collected during magnetic resonance diagnostic examinations in Radiology Department of St. John's Cancer Center in Lublin, eastern Poland, in 2011-2012. The protocol was fully approved by Institutional Review Board, but according to the national law no written permission was obtained from patients, since personal data was not presented and analyzed throughout the study and in the final report.

Sixty one Caucasian women (age 26-76 year) with histologically-proved squamous cell carcinoma were randomly selected for the study. All patients were in stage I/ IIA or higher according to FIGO classification [7]. Those with any form of gynaecological surgery (except cesarean section) or oncological treatment throughout whole life or abdominal surgery in last year excluded from the study group. Clinical and demographical data was obtained from medical records. No additional questionnaire examinations were performed.

All studies were performed on 1.5T MR scanner (Achieva; Philips Medical Systems; Veenpluis, The Netherlands) according to the standard protocol for pelvis imagining, which included routine coronal, sagittal and axial series $[7,8]$. The field of view varied depending on the examined area and patient size, while section thickness was constant and kept at $4 \mathrm{~mm}$. The following sequence were performed: T1- and T2weighted turbo spin echo, with (SPIR - Spectral Presentation with Inversion Recovery) and without fat suppression and WAVE (Water Selective Volume Excitation), diffusion weighted images (DWI; $b=0,300$ and $600 \mathrm{~s} / \mathrm{mm}^{2}$ ) followed by ADC map (Apparent Diffusion Coefficient). Additional coronal (dynamic and static) and sagittal T1-weighted image (static) was performed after gadolinium-diethylenetriamine-penta-acetic acid (Gd-DTPA) injection $(0.1 \mathrm{mg} / \mathrm{kg})$. Data was stored on the picture archiving and communication system (PACS) and examined by radiologists on Extended MR Work Space 2.6.3.4. (Philips Medical Systems; Veenpluis, The Netherlands).

According to the radiological standards [7], the longest linear dimension (RL - right-left, AP - antero-posterior, CC - cranio-caudal) of the tumour was measured in the 3 principal anatomical plates on T2-weightd images. Using multiplanar reconstruction (MPR) options a tumour volume was calculated on T2-weighted images. The size and number of enlargements surrounding lymphatic nodes were also evaluated. On the axial T2-weighted images, the tumour and lymph node area was selected and obtained ROI was copied on DWI and ADC map (dDWI; b600 s/ $\mathrm{mm}^{2}$ ). Finally, the ADC value was automatically generated.

The obtained data was statically evaluated using Statistica 9.0. The distribution of continuous data was analyzed by Shapiro-Wilk test, and differences evaluated by t-Student or Mann-Whitney $U$ test. The nominal scale measures were analyzed by $\chi^{2}$ Fischer exact test. To evaluate the odds ratio (OR), a 95\% coefficient interval $(95 \% \mathrm{CI})$ was calculated. Data was presented by mean (M), standard deviation (SD) and median $(\mathrm{Me})$. The 0.05 level of probability $(p<0.05)$ was used as the criterion of significance.

\section{RESULTS}

From among the examined patients, 22 women were from rural and 39 from urban areas (Tab. 1). The village residents were insignificantly older. Their first and last menstruation was observed later and number of pregnancies was higher than that in urban women. However, the incidence of miscarriage was insignificantly lower. Cesarean section was performed only in one case in a rural resident and in 3 three urban women.

Table 1. Demographic and previous gynaecological data in relation to place of residence

\begin{tabular}{lccccccc}
\hline & \multicolumn{3}{c}{ Rural } & \multicolumn{5}{c}{ Urban } & \multirow{2}{*}{$\mathrm{p}$} \\
\cline { 2 - 7 } & $\mathrm{n}$ & $\mathrm{M}$ & $\mathrm{SD}$ & $\mathrm{n}$ & $\mathrm{M}$ & $\mathrm{SD}$ & \\
\hline Age (years) & 22 & 59.09 & 8.39 & 39 & 57.79 & 10.32 & 0.6173 \\
\hline Menarche (year) & 22 & 14.55 & 1.44 & 39 & 14.18 & 1.83 & 0.4236 \\
\hline Last menstruation (year) & 22 & 50.64 & 5.20 & 39 & 49.82 & 6.04 & 0.5968 \\
\hline No. of pregnancies & 19 & 3.32 & 1.89 & 37 & 3.11 & 1.56 & 0.8287 \\
\hline No. of miscarriages & 6 & 1.17 & 0.41 & 9 & 2.11 & 1.17 & 0.1407
\end{tabular}

In all examined cases cervical cancer presented typical radiological morphology (fig. 1). All the linear diameters of the tumor as well as their volume were insignificantly higher in rural residents, when compared with urban women (Tab. 2).

Table 2. Linear diameters $(\mathrm{mm})$ and volume $\left(\mathrm{mm}^{3}\right)$ of the cervical cancer in relation to the place of residence

\begin{tabular}{lccccccc}
\hline & \multicolumn{3}{c}{ Rural } & \multicolumn{5}{c}{ Urban } & \multirow{2}{*}{$\mathrm{p}$} \\
\cline { 2 - 7 } & $\mathrm{n}$ & $\mathrm{M}$ & $\mathrm{SD}$ & $\mathrm{n}$ & $\mathrm{M}$ & $\mathrm{SD}$ & \\
\hline Horizontal & 22 & 59.82 & 15.37 & 39 & 53.18 & 15.18 & 0.2537 \\
\hline Saggital & 22 & 59.91 & 20.49 & 39 & 51.18 & 18.90 & 0.1493 \\
\hline Vertical & 22 & 65.82 & 25.85 & 39 & 54.03 & 18.42 & 0.0763 \\
\hline Volume & 22 & 101.18 & 80.63 & 39 & 75.49 & 55.19 & 0.3919 \\
\hline
\end{tabular}

The ADC value of the cervical tumour was insignificantly lower while $\mathrm{ADC}$ of lymphatic nodes was higher in rural women (Tab. 3).

Table 3. ADC value $\left(\times 10^{-3} \mathrm{~mm}^{2} / \mathrm{s}\right)$ of the cervical tumor and the biggest enlarged lymphatic nodules in relation to the place of residence

\begin{tabular}{lccccccc}
\hline & \multicolumn{4}{c}{ Rural } & \multicolumn{5}{c}{ Urban } & $\mathrm{p}$ \\
\cline { 2 - 7 } & $\mathrm{n}$ & $\mathrm{M}$ & $\mathrm{SD}$ & $\mathrm{n}$ & $\mathrm{M}$ & $\mathrm{SD}$ & \\
\hline Tumor & 22 & 0.90 & 0.21 & 39 & 0.97 & 0.21 & 0.2444 \\
\hline Lymphatic nodules & 16 & 0.94 & 0.11 & 23 & 0.86 & 0.12 & 0.0655 \\
\hline
\end{tabular}

Insignificant changes in tumour grade between both examined groups were found in histological, clinical and radiological examinations (Tab. 4).

Place of residence did not influence any clinical symptoms or the tumour volume and its ADC (Tab. 5). Colporrhoea 

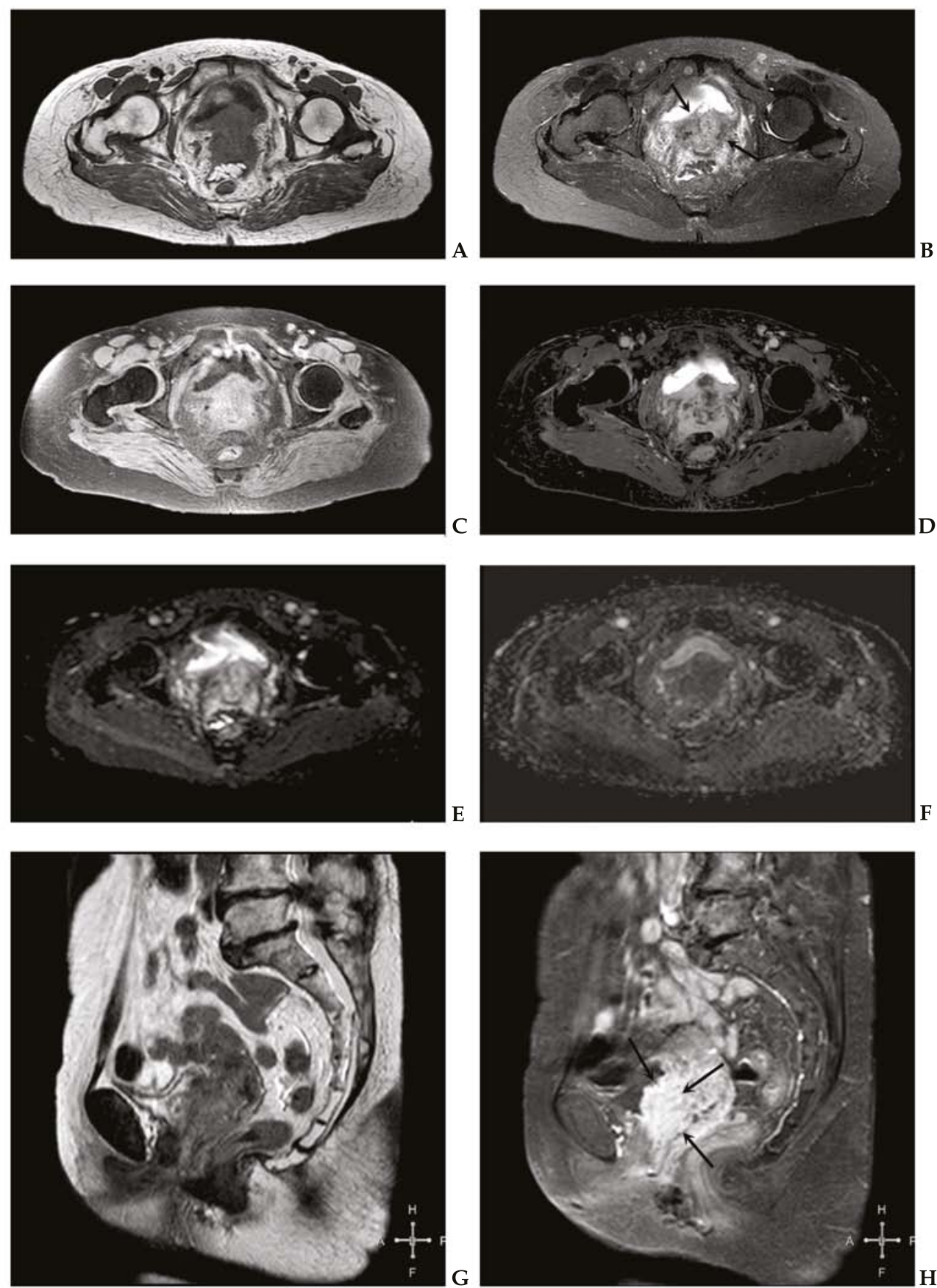

Figure 1. Magnetic resonance of advance cervical cancer (stage IVb; T3N2M1) with internal degenerative changes (arrows). Axial T1-weighted (A), T2-weighted (B), fat saturated T1-weighted (C), fat saturated T1-weighted post-contrast (D), diffusion weighted images on b600 s/mm² (E) and ADC map (F). Saggital T1-weighted (G) and fat saturated T1-weighted post- contrast (H) images 
Table 4. Histological, clinical and radiological grading of the cervical cancer in relation to the place of residence

\begin{tabular}{|c|c|c|c|c|c|}
\hline & & & & & \\
\hline & $\mathrm{n}$ & $\%$ & $\mathrm{n}$ & $\%$ & \\
\hline Histo & & & & & \\
\hline $\mathrm{Gl}$ & 1 & 4.55 & 3 & 7.69 & \\
\hline GII & 15 & 68.18 & 27 & 69.23 & 0.8494 \\
\hline GIII & 6 & 27.27 & 9 & 23.08 & \\
\hline Clinic & & & & & \\
\hline GI & 0 & 0.00 & 3 & 7.69 & \\
\hline GII & 3 & 13.64 & 12 & 30.77 & \\
\hline GIII & 18 & 81.82 & 23 & 58.97 & \\
\hline GIV & 1 & 4.55 & 1 & 2.56 & \\
\hline Radic & & & & & \\
\hline GII & 1 & 4.55 & 5 & 12.82 & \\
\hline GIII & 16 & 72.73 & 29 & 74.36 & 0.3830 \\
\hline GIV & 5 & 22.73 & 5 & 12.82 & \\
\hline
\end{tabular}

Table 5. Clinical symptoms and selected radiological data in relation to the place of residence

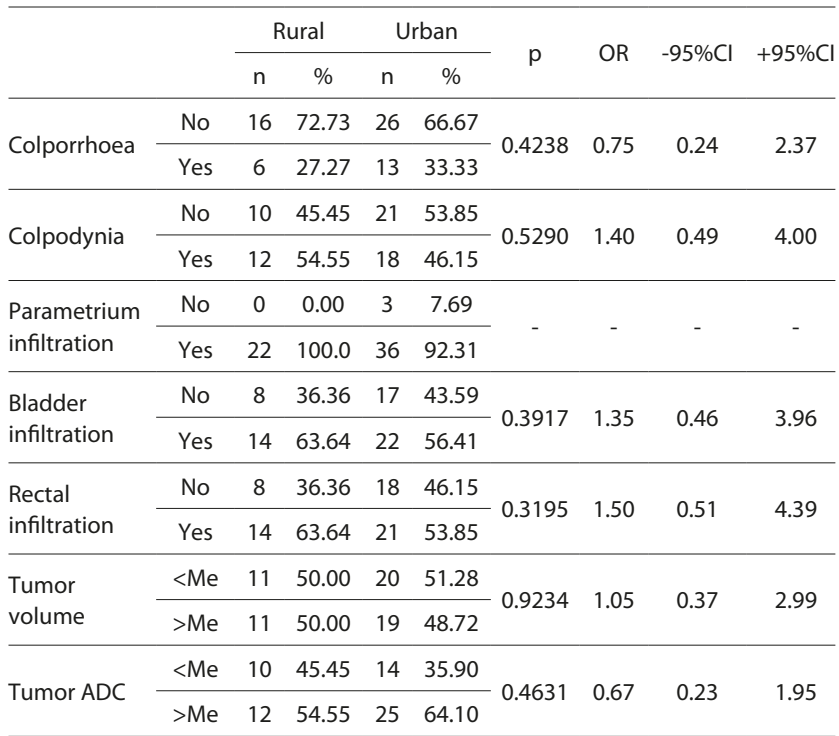

No - lack of parameter, yes - presence of the parameter

and colpodynia were insignificantly more often observed in urban women. However, parametrium, urinary bladder and rectal infiltrations were more commonly seen among rural residents.

Place of residence slightly influenced pathological enlargement of lymphatic nodes (Tab. 6). Higher risk of lymphatic spread to the internal iliac and parametral lymphatic nodes was reported in patients from the rural community.

\section{DISCUSSION}

The obtained data indicates a low influence of place of residence on clinical symptoms and radiological parameters of cervical cancer. The only exception was higher risk of pathological enlargement of internal iliac and parametrial lymph nodules among women from the rural community. Moreover, in that group, insignificantly higher linear diameters and volume
Table 6. Pathological enlargement of various groups of pelvic lymphatic nodes in relation to the place of residence

\begin{tabular}{|c|c|c|c|c|c|c|c|c|c|}
\hline & & & ural & & rban & & & & \\
\hline & & $\mathrm{n}$ & $\%$ & $n$ & $\%$ & $p$ & UR & $-95 \% \mathrm{Cl}$ & $+95 \% \mathrm{Cl}$ \\
\hline Right common & No & 13 & 59.09 & 23 & 58.97 & & & & \\
\hline iliac & Yes & 9 & 40.91 & 16 & 41.03 & 0.0049 & 1.00 & 0.34 & \\
\hline Left common & No & 12 & 54.55 & 20 & 51.28 & ค & (2000 & 00 & 250 \\
\hline & Yes & 10 & 45.45 & 19 & 48.72 & & 0.00 & & \\
\hline Right internal & No & 8 & 36.36 & 21 & 53.85 & 017 & 200 & ק 70 & - \\
\hline & Yes & 14 & 63.64 & 18 & 46.15 & & & & \\
\hline Left internal & No & 7 & 31.82 & 21 & 53.85 & 1016 & & Pि & \\
\hline iliac & Yes & 15 & 68.18 & 18 & 46.15 & 0.0810 & 2.30 & 0.84 & 1.48 \\
\hline Right external & No & 17 & 77.27 & 30 & 76.92 & & م00 & 20 & 200 \\
\hline iliac & Yes & 5 & 22.73 & 9 & 23.08 & $0.61 / 8$ & 0.98 & 0.28 & 3.40 \\
\hline Left external & No & 17 & 77.27 & 31 & 79.49 & 05115 & 111 & 027 & 109 \\
\hline iliac & Yes & 5 & 22.73 & 8 & 20.51 & 0.5415 & 1.14 & 0.32 & 4.04 \\
\hline Right & No & 5 & 22.73 & 18 & 46.15 & 60 & 201 & & \\
\hline parametrial & Yes & 17 & 77.27 & 21 & 53.85 & 0.0604 & 2.91 & 0.90 & 9.48 \\
\hline & No & 6 & 27.27 & 19 & 48.72 & & & & \\
\hline parametrial & Yes & 16 & 72.73 & 20 & 51.28 & & 2.33 & 0.82 & 1.83 \\
\hline
\end{tabular}

No - lack of lymph node enlargement, yes - presence of lymph node enlargement

of the tumour as well as tumor ADC value were revealed. The latter abnormality is probably secondary to necrosis and haemorrhage into the tumour, which were proved by MR examination using classical sequence, such as T1- and T2-weighted TSE, SPAIR and WAVE. Generally, the ADC value and low signal on DWI images indicate high local cellularity and movements of molecules, which is typical for malignances and inflammation, but both pathologies could be distinguished on T2-weighted images [7,8]. A high signal on DWI and low ADC value is usually observed in highly vascular neoplastic areas, and a low signal on DWI and high ADC value in necrotic areas. DWI is strongly dependent on the $b$ vales during MR examination. For this reason, the main limitation of the study is the low number of selected b (b0, 300, 600), which has recently been increased in our department $\left(\mathrm{b} 0,50,100,500,1000 \mathrm{~s} / \mathrm{mm}^{2}\right)$. However, even with the two $b$ levels, it was possible to distinguish internal differences between examined groups. A more inhomogeneous structure, larger size and higher incidence of lymphatic spread indicates higher disease progression among rural inhabitants. Another important limitation of the current study is the lack of histopathological diagnosis for enlarged lymphatic nodes. However, their radiological morphology fully corresponds with the standard description of lymph nodes metastates $[8,9]$. Because of that, such abnormalities were always interpreted as neoplastic infiltration.

All obtained radiological parameters are very important for clinicians. In the case of an advanced stage of the disease with parametrial, vesicle, rectal and low vaginal infiltration, as well as distal lymphatic and other metastasis, surgical treatment is not recommended and the patient should be treated with radio- or radio-chemotherapy [10]. The mean tumour volume among the whole examined population was relatively high $\left(84.75 \pm 66.02 \mathrm{~mm}^{3}\right)$, but similar to other studies [11-14]. The parameter is also a very important prognostic factor. According to Hunjung et al. [11], women with a tumour volume over $30 \mathrm{~mm}^{3}$ are less sensitive to treatment and more 
often present local and/or distal progression. Similar data has been presented by other authors [12-13]. It is also important that in large tumours the lymphadenopathy is more often observed [10, 15]. Moreover, a 5-year survival in patients with initial lymphatic spread was reported for only about $39-54 \%$, while without lymph node involvement reaches $67-92 \%$ [10]. Also, the ADC value is an important prognostic factor. It usually increases during therapy and indicates good treatment-response, even without significant changes in the tumour size [16]. However, the absolute values obtained in various study vary $\left(0.88-1.6 \times 10^{-3} \mathrm{~mm}^{2} / \mathrm{s}\right)$, impractically due to b-related differences. Although ADC international standardization does not exist, the concomitant ADC evaluation in both tumour and lymphatic nodules may be helpful for early diagnosis of lymph nodes metastases, even in normal-sized organs [9].

It should be mentioned that cervical cancer is not the only disease that is related to the place of residence. Similar data was obtained for various neoplasms [17-11]. In malignant melanoma and skin cancers, rural residents are exposed to higher doses of UV radiation, which is a crucial risk factor for those diseases [17]. However, pulmonary and laryngeal cancers are smoke-dependent and their higher incidence is probably secondary, not only to higher cigarette smoking, but also lower access to health care $[18,19]$. As pointed out above, cervical cancer does not have any specific or significant environmental risk factor. Its incidence is related especially to sexual behavior and HPV infections, and based on current data, the tumour growth is similar between rural and urban residents [3-6]. The differences in size my be only related to early diagnosis in urban residents who have better access to specialized medical care and better education [18-22]. Advanced stages of reported patients are probably related to the hospital where the study was performed, since it is the only regional radiotherapy centre in central-eastern Poland. In less advanced cases, surgical treatment was performed in another hospital and for this reason such group of women was lost to the study. Sixty-one currently evaluated patients is a relatively small group; however, the quantity is similar to most of the above-cited articles. Moreover, since all women were randomly selected to the study, the reported data is representative at least for central-eastern Poland. It should be also pointed out that cervical cancer in one of the disease covered by the National Cancer Control Programme established by the Polish Parliament in 2005. Despite all the efforts, including personal mailing carried out according to regulation of Cervical Cancer Population Screening Programme and wide mass media advertisement, in $2007-2009$, only $24.24 \%$ of the invited women $(9,727,842)$ participated in the fully refundable cytology [23]. Such unsatisfactory health activity may increase the incidence of evaluated malignance in a near future.

\section{CONCLUSION}

Based on the magnetic resonance data, cervical cancer has a similar morphology and growth pattern among rural and urban women. However, an insignificantly bigger tumour size in rural residents may indicate a higher incidence of lymph nodes metastasis, probably due to lower health care. Since the study was conducted on a limited number of patients, the obtained data should be confirmed in a larger epidemiological and mulicentre study.

\section{REFERENCES}

1. Ferlay J, Shin HR, Bray F, Forman D, Mathers CD, Parkin D. GLOBOCAN 2008. Cancer Incidence and Mortality Worldwide: IARC CancerBase No. 10. Lyon, France: International Agency for Research on Cancer; Year. Available at: http://globocan.iarc.fr. 2010. (accessed 20/07/2013).

2. Klimek M, Kruczak A, Ryś J, Mularz K, Halaszka K, Przewoźnik M, et al. Clinico-morphological parameters affecting survival of patients with advanced cervical cancer. Pol J Pathol. 2011; 62(4): 250-256.

3. Mocarska A, Starosławska E, Żelazowska-Cieślińska I, Łosicki M, Stasiewicz D, Kieszko D, et al. Epidemiology and risk factors of the cervical squamous cell carcinoma. Pol Merkur Lekarski. 2012; 33(194): $101-106$.

4. Jarząbek-Bielecka G, Durda M, Sowińska-Przepiera E, Kaczmarek M, Kędzia W. Sexual activity among young women. Medical and legal aspects. Ginekol Pol. 2012; 83(11): 827-834.

5. Schluterman NH, Sow SO, Traore CB, Bakarou K, Dembelé R, Sacko $\mathrm{F}$, et al. Differences in patterns of high-risk human papillomavirus infection between urban and rural low-resource settings: crosssectional findings from Mali. BMC Womens Health. 2013; 13: 4.

6. Biraro S, Ruzagira E, Kamali A, Whitworth J, Grosskurth H, Weiss HA HIV-1 transmission within marriage in rural Uganda: a longitudinal study. PLoS One. 2013; 8(2): e55060.

7. Freeman SJ, Aly AM, Kataoka MY, Addley HC, Reinhold C, Sala E. The revised FIGO staging system for uterine malignancies: implications for MR imaging. Radiographics. 2012; 32(6): 1805-1827.

8. Balleyguier C, Sala E, Da Cunha T, Bergman A, Brkljacic B, Danza F, et al. Staging of uterine cervical cancer with MRI: guidelines of the European Society of Urogenital Radiology. Eur Radiol. 2011; 21(5): 1102-1110.

9. Lin G, Ho KC, Wang JJ, Ng KK, Wai YY, Chen YT, et al. Detection of lymph node metastasis in cervical and uterine cancers by diffusionweighted magnetic resonance imaging at 3T. J Magn Reson Imaging. 2008; 28(1): 128-135.

10. Liyanage SH, Roberts CA, Rockall AG. MRI and PET scans for primary staging and detection of cervical cancer recurrence. Womens Health (Lond Engl). 2010; 6(2): 251-267.

11. Hunjung K, Woochul K, Mijo L, Song E, Loh JK. Tumor volume and uterine body invasion assessed by MRI for prediction of outcome in cervical carcinoma treated with concurrent chemotherapy and radiotherapy. Jpn J Clin Oncol. 2007; 37(11): 858-866.

12. Jońska-Gmyrek J, Żółciak-Siwińska A, Gmyrek L, Staniaszek J, Lindner $\mathrm{B}$, Andrzejuk J. Influence of tumor diameter on treatment results in cervical cancer patients. Ginekol Pol. 2012; 83(8): 576-580.

13. Olsen JR, Esthappan J, DeWees T, Narra VR, Dehdashti F, Siegel BA, et al. Tumor volume and subvolume concordance between FDG-PET/ $\mathrm{CT}$ and diffusion-weighted MRI for squamous cell carcinoma of the cervix. J Magn Reson Imaging. 2013; 37(2): 431-434.

14. Esthappan J, Ma DJ, Narra VR, Raptis CA, Grigsby PW. Comparison of apparent diffusion coefficient maps to T2-weighted images for target delineation in cervix cancer brachytherapy. J Contemp Brachytherapy. 2011; 3(4): 193-198.

15. Pointreau Y, Ruffier Loubière A, Denis F, Barillot I. Cervix cancer. Cancer Radiother. 2010; 14(Suppl 1): S147-S153.

16. Kuang F, Ren J, Zhong Q, Liyuan F, Huan Y, Chen Z. The value of apparent diffusion coefficient in the assessment of cervical cancer. Eur Radiol. 2013; 23(4): 1050-1058.

17. Pérez-Gómez B, Aragonés N, Gustavsson P, Lope V, López-Abente G, Pollán M. Socio-economic class, rurality and risk of cutaneous melanoma by site and gender in Sweden. BMC Public Health. 2008; 8: 33.

18. Schouten LJ, Meijer H, Huveneers JA, Kiemeney LA. Urban-rural differences in cancer incidence in The Netherlands 1989-1991. Int J Epidemiol. 1996; 25(4): 729-736.

19. Ocaña-Riola R, Sánchez-Cantalejo C, Rosell J, Sánchez-Cantalejo E, Daponte A. Socio-economic level, farming activities and risk of cancer in small areas of Southern Spain. Eur J Epidemiol. 2004; 19(7): 643-650.

20. Maślach D, Krzyżak M, Szpak A, Owoc A, Gębska-Kuczerowska A, Bielska-Lasota M. Differences in results of breast cancer curative treatment between urban/rural female population in Podlaskie Voivodship of Poland before introduction of the National Cancer Control Programme. Ann Agric Environ Med. 2013; 20(1): 68-71.

21. Pons-Vigués M, Puigpinós-Riera R, Serral G, Pasarín MI, Rodríguez $\mathrm{D}$, Pérez G, et al. Knowledge, attitude and perceptions of breast cancer screening among native and immigrant women in Barcelona, Spain. Psychooncology. 2012; 21(6): 618-629.

22. Levin KA, Davies CA, Douglas GV, Pitts NB. Urban-rural differences in dental caries of 5-year old children in Scotland. Soc Sci Med. 2010; 71(11): 2020-2027.

23. Spaczyński M, Karowicz-Bilinska A, Rokita W, Molińska-Glura M, Januszek-Michalecka L, Seroczyński P, et al. Attendance rate in the Polish Cervical Cancer Screening Program in the years 2007-2009. Ginekol Pol. 2010; 81(9): 655-663. 